ORIGINAL ARTICLE

\title{
Pediatric window falls: not just a problem for children in high rises
}

\author{
N L Vish, E C Powell, D Wiltsek, K M Sheehan
}

Injury Prevention 2005;11:300-303. doi: 10.1136/ip.2005.008664

\begin{abstract}
See end of article for authors' affiliations

.....................

Correspondence to: $\operatorname{Dr} N \mathrm{~L}$ Vish, Division of Emergency Medicine, Cincinnate Children's Hospital, 3333 Burnet Avenue, Cincinnati, $\mathrm{OH}$, USA; nora.vish@cchmc. org
\end{abstract}

Accepted 4 May 2005
Background: Window falls are a frequent cause of injury (15/100 000) among Chicago preschool children. In Boston and New York, public health efforts have successfully decreased window fall injuries. Local data are needed to develop appropriate interventions for Chicago.

Objective: To describe the housing characteristics and types of injuries among children who fell from windows treated in a Chicago pediatric trauma center.

Methods: Children treated in a pediatric trauma center for injuries related to window falls between 1995 and 2002 were identified retrospectively. We reviewed family demographics, the circumstances of the fall, and types of injuries. Site visits were performed to determine the height and type of building and type of window where the fall took place.

Results: The authors reviewed 90 cases; 55 were male. The median age was 2 years. Ninety eight percent of falls were reported to be from the third floor or lower. Site visits $(n=77)$ showed that $96 \%$ of the buildings were four storeys or lower. The median length of hospital stay was two days (range 0-24 days). The most common injuries were head trauma and extremity fractures. Three patients died, and an additional three patients were discharged to rehabilitation centers.

Conclusions: Some window falls result in serious injury. In Chicago, most falls were from modest heights (2nd/3rd floor windows) in buildings of four or fewer storeys, rather than from "high rises". Strategies to prevent window falls should be directed to the owners and occupants of this type of housing.
$\mathrm{F}$ alls are the leading cause of unintentional injury among children in the United States. Annually, 2.3 million children ages 14 years and younger require emergency room care for fall related injuries. ${ }^{1}$ Falls from windows are of particular concern because they often result in severe injuries. Community education and installation of window guards in several cities have successfully decreased the incidence of window falls among children. The initiative in New York City, called "Children Can't Fly" included an extensive educational campaign targeted to parents and the distribution of free window guards. ${ }^{2}$ In 1976 a city health code was added, mandating that all owners of multiple dwellings provide window guards where children 10 years or younger reside. This initiative resulted in a $96 \%$ decrease in the incidence of unintentional window falls. ${ }^{3}$

The Boston programme, "Kids Can't Fly" involved a comprehensive educational campaign and a voluntary ordinance encouraging landlords to install window guards. ${ }^{4}$ Programme leaders observed that while individual tenants were well intentioned, they often failed to complete the installation of the free guards. A critical component of the success of the programme was the active involvement of property managers. The managers of mid-sized, low and moderate income properties were encouraged to install guards purchased through a programme that matched the amount spent by property owners. The "Kids Can't Fly" programme resulted in an $83 \%$ decrease in the number of window falls in Boston in the two year period after its initiation.

Each year there are an estimated 15 window falls per 100000 Chicago preschool children. ${ }^{5}$ Information is needed to better understand this issue among Chicago children so as to develop appropriate interventions to prevent window falls. The purpose of this study is to describe the demographic characteristics of children who fell from windows in Chicago, to perform site visits to determine the heights and types of buildings that children fell from, and to quantify the injuries resulting from window falls.

\section{METHODS}

Children treated in a level I pediatric trauma center for injuries related to window falls between 1995 and 2002 were identified retrospectively using the ICD9 external cause of injury code (E882) for fall from a building. Cases were included if they met the following criteria: (1) the fall occurred from a window and (2) the fall was unintentional. Information collected from the records included patient demographics, circumstances (floor of fall, landing surface), anatomic areas injured, Glasgow Coma Score (GCS) on arrival to the emergency department, number of inpatient hospital days, and inhospital death or patient disposition. Social worker notes that reconstructed, in text form, the circumstances leading to the fall were reviewed to gather specific information about the supervision of the child, if there was furniture near the window, and if it had a screen.

The second phase of the study included site visits to the location of the fall to describe the type of building, the total number of floors in the building, and the type of window the child fell through. Building types were designated as houses (one or two family), townhouses, or multiple unit dwellings. Building height was described as the number of floors. Window type was described as single hung, double hung, sliding, or casement. Some of the buildings in Chicago include "garden" units in which one to four feet is below grade. Windows in garden units were considered first level; windows in the floor above were designated second level. We estimated the height of the fall by measuring the vertical height of a brick, or siding panel, and counting vertically to the reported window.

Abbreviations: GCS, Glasgow Coma Score. 


\begin{tabular}{|lc|}
\hline \multicolumn{2}{|l|}{ Table 1 Circumstances of falls } \\
\hline \multicolumn{2}{l}{$\mathbf{n}(\%)$} \\
\hline Floor of fall \\
1 & $11(12)$ \\
2 & $53(59)$ \\
3 & $24(27)$ \\
4 & $1(1)$ \\
5 & $1(1)$ \\
Window covering & $31(34)$ \\
Screen & $18(20)$ \\
Open & $5(6)$ \\
Other covering & $2(2)$ \\
Unlocked by child & $34(38)$ \\
Not documented & $44(49)$ \\
Surface of fall & $22(24)$ \\
Concrete & $5(6)$ \\
Grass/dirt & $19(21)$ \\
Vegetation & \\
Not documented & \\
\hline & \\
\hline
\end{tabular}

\section{RESULTS}

\section{Demographics}

Ninety children were treated for injuries resulting from window falls during the seven year study period. Fifty five were males. The age range was 9 months to 16 years with a median of 2 years (mean age 3 years 2 months). Ninety percent were 5 years old or younger. Five of the 12 children 6 years old or older were developmentally delayed. Forty nine percent of families self identified as Hispanic, 36\% as other/ unknown, $8 \%$ white, and $7 \%$ black. Seventy four percent were enrolled in Illinois Medicaid, $20 \%$ had HMO/PPO or other insurance, and $6 \%$ had no insurance.

\section{Circumstances of falls record review}

Eighty eight children (98\%) fell from a window in the third floor or lower (table 1). Presence or absence of a screen was documented in 56 cases. Of these, 31 (55\%) reported the presence of a screen. In five cases the window had some other type of covering (mosquito netting, plastic, glass). None reported having a window safety guard. The fall surface was described as concrete in almost half the cases (49\%).

In $23 \%$ a bed or couch was present near the window at the time of the fall. A parent reported being in the same house/ apartment as the child in 53\% of the falls, $13 \%$ had an adult that was not the primary caretaker in the house, $2 \%$ had a

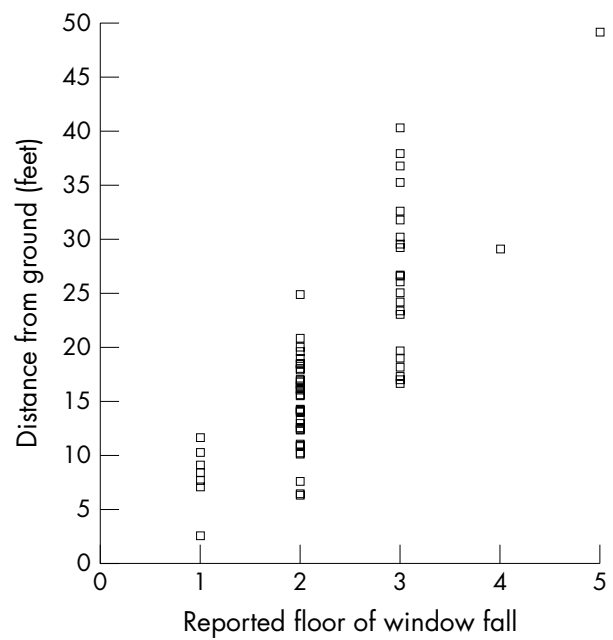

Figure 1 Relation between floor of window fall and the measured height of window. minor supervising (older sibling, relative), $1 \%$ had no supervision, 31\% unknown/not documented.

More than half of window falls were during the summer, with 53 falls occurring between June and August. Forty eight percent of the falls occurred between the hours of noon and $6 \mathrm{pm}, 34 \%$ between $6 \mathrm{pm}$ and midnight, $16 \%$ between $6 \mathrm{am}$ and noon, and $2 \%$ between midnight and $6 \mathrm{am}$.

\section{Site visits}

We completed 77 site visits, representing $85 \%$ of the window falls in this study. Falls that occurred in buildings outside of the city of Chicago $(n=7)$ and those where the address was incorrect $(n=6)$ were not included. Seventy four buildings $(96 \%)$ had four or fewer storeys. There were three falls from windows in high rise buildings: these buildings were 26,10 , and seven storeys and the falls occurred from the second, fifth, and third floors respectively. Fifty seven (74\%) falls were through windows in multi-unit dwelling buildings, 19 $(25 \%)$ occurred in homes, and one (1\%) was through a townhouse window. Seventy two (95\%) of the windows were single or double hung, two windows $(3 \%)$ were sliding windows, and two windows (3\%) were casement windows; in one building the windows were being renovated.

Figure 1 shows the reported floor of the fall and the distance of the fall estimated during the site visit. The estimated distances of falls reported as through first floor windows ranged from 2.5 feet to 11.5 feet. Falls reported as second floor falls ranged from 6.25 feet to 25 feet, and those reported as third floor falls ranged from 16.6 feet to 40.25 feet in distance. The median height of fall was 17 feet.

\section{Outcome}

Significant anatomic injuries are shown in table 2. Head trauma was the most common injury $(48 \%)$, followed by skeletal injuries (23\%). Thirteen percent had injuries to the chest or pelvis. Abdominal injuries accounted for only 3\% of injuries. Twenty nine patients $(32 \%)$ had minor injuries and are not included in the table. The GCS in the emergency department ranged from 3 to 15 . Nineteen had a GCS $\leqslant 13$ and five had GCS $\leqslant 8$. Among the 19 children with a GCS $\leqslant 13$, seven $(37 \%)$ had falls shorter than, or equal to 17 feet (missing data, $\mathrm{n}=1$ ). Among the 56 children with GCS of 14-15, 31 had falls less than 17 feet and 25 had falls greater than 17 feet (missing data, $\mathrm{n}=10$ ). Among the five children with GCS $\leqslant 8$, one had a fall shorter than 17 feet. The length of hospital stay ranged from 0 to 24 days; the median length of stay was two days. Eighty four children were discharged to home and three were discharged to rehabilitation facilities. Three children died, each from head trauma. Their reported height and estimated fall distances were first floor (10.25 feet), second floor (17.75 feet), and third floor (38 feet). The ages of the children who died were 9 months, one and a half years, and 2 years.

Table 2 Major injuries

\begin{tabular}{llc}
\hline Injury type & Specific injury & Injuries $(\mathbf{n})^{*}$ \\
\hline Head $(n=43)$ & Skull fracture & 30 \\
& Intracranial contusion & 21 \\
\multirow{2}{*}{ Chest/pelvis $(n=12)$} & Intracranial hemorrhage & 2 \\
& Hemothorax/pneumothorax & 2 \\
& Rib fracture & 5 \\
Abdomen $(n=3)$ & Pelvic fracture & 5 \\
\multirow{2}{*}{ Skeletal $(n=21)$} & Liver laceration & 2 \\
& Splenic rupture & 1 \\
& Upper extremity & 8 \\
& Lower extremity & 14 \\
\hline
\end{tabular}

*Several patients had multiple types of injury within a category 


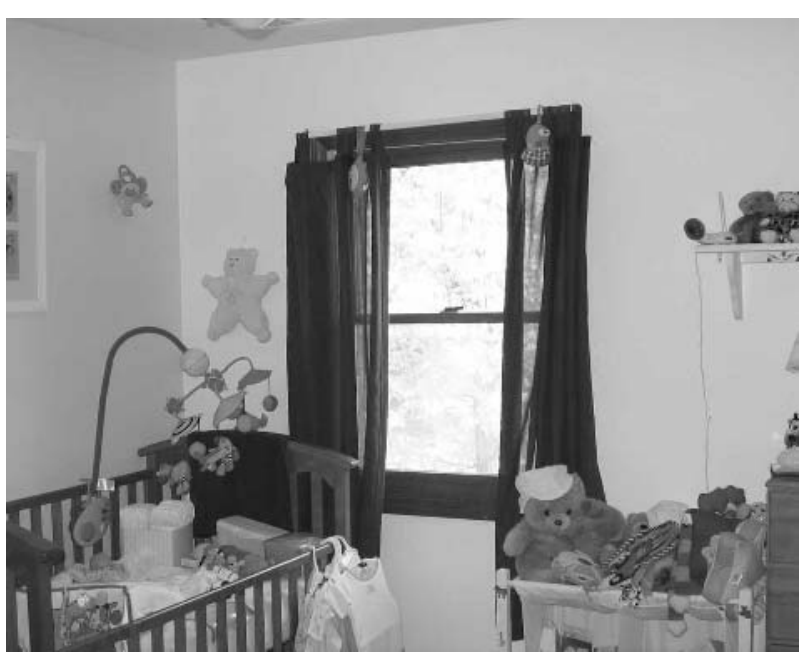

Figure 2 A double hung window in a child's bedroom.

\section{DISCUSSION}

These data from Chicago indicate most children fell from first, second, or third floor windows in buildings that were four or fewer storeys high. Site visits suggest there is much overlap in the actual fall heights reported to be from first and second floor windows, and between second and third floor windows. Although most children in Chicago fall from lower floors, our data show a significant degree of morbidity and mortality from these falls. Almost half of falls occurred between noon and $6 \mathrm{pm}$ and many children were reportedly supervised at the time of the fall.

Others have reported demographic findings similar to those we observed, with males 5 years old or younger accounting for the majority of those injured in window falls. ${ }^{6-9}$ In our data a significant proportion (42\%) of children who were older than 5 years old were described as developmentally delayed. Using Medicaid as a proxy for socioeconomic status, we found low income children to account for $74 \%$ of those injured in window falls. Children with Medicaid account for $60 \%$ of those treated in the Children's Memorial Hospital emergency department and $30 \%$ of children statewide in Illinois. ${ }^{10}$ This likely represents housing patterns in Chicago: families with lower income live in buildings that lack air conditioning, and may have no alternatives for cooling the living space other than opening the windows wide. Similar to studies in Los Angeles, London, and New York, the incidence of window falls increased during the hot summer months. ${ }^{2} 811$

Other environmental conditions and parent supervision behaviors associated with window falls are less clear. More than half the falls occurred when a parent was in the home/ apartment. Parents may perceive window screens as effective fall barriers: $55 \%$ of the falls occurred when a window screen was in place. These data suggest that household furniture was a contributing factor in almost one fourth of falls. Parents may be unaware that household furniture placed under windows could put a child at risk of a window fall by giving a child easy access to the window opening. Another possibility is that furniture may be placed near windows because alternative sites are limited in crowded households. Additional work is needed to better understand window fall circumstances.

A review of falls from Dallas apartments reported that $94 \%$ of the falls occurred from three storeys or less. ${ }^{7}$ This is unlike the experience in the northeast, and similar to the data we report. In addition, in Dallas window falls were through windows that were within 2 feet of the floor, within the reach of a young child. In Chicago, the building code requires window guards if the height of the window sill is less than 2 feet above the floor. We do not know how well this code is enforced and its potential effectiveness to prevent window falls. As the site visits were limited to the exterior of the building, we cannot report the distance between the sill and the floor inside. It may be that lower windows lacked guards, or that children fell from windows more than 2 feet from the floor. The data suggest that furniture placed near some of the windows was a contributing factor to the fall, allowing children access to the higher windows.

In Chicago, the reported floor of a fall is a poor indicator of the height of the fall. In these data, a fall reported from the second floor may represent a 6-25 foot fall. In part this variation is explained because windows in submerged "garden level" units are very near the ground (building codes allow habitable space in a residence to be up to half submerged) and windows the next level up, reported as "second floor", were not very high. These data are unique in that the performance of the site visits allowed us to estimate the actual distance of the fall and compare that to the reported floor of fall.

Falls from windows in Chicago resulted in significant injuries. Head trauma was the most common injury (48\%) followed by skeletal trauma (23\%). The three children with fatal injuries fell from the heights of 10.25 feet, 17.75 feet, and 38 feet (all reported from the third floor or lower). This is in contrast to New York data that report $100 \%$ survival in children who fell three storeys or less, and a Dallas case series in which there were no deaths among 98 children who fell from four floors or lower. ${ }^{37}$

Because this was in part a retrospective study, we were limited to the medical record for details of the injury event. Not all parents were asked if furniture was near windows, or if a screen was present, thus reported percentages may underrepresent these circumstances. The data are not population based, and represent the experience at a single pediatric trauma center in Chicago. However, these data suggest that in young children falls from relatively modest heights are associated with significant morbidity, and interventions to prevent them are warranted.

Although the hazard that window falls pose to children's health has been recognized, additional work is needed to implement the recommended preventative strategies suggested by the American Academy of Pediatrics in a recent policy statement. ${ }^{12}$ Window falls prevention programmes, which include broad based public education, can be used to decrease incidence of pediatric window falls in urban centers. Successful interventions have been implemented by New York and Boston. This study identifies preschool children, particularly those living in poverty, as the at-risk population in Chicago. We have initiated local efforts including posters on the public transit system and community outreach programmes in several Hispanic neighborhoods near the hospital emphasizing the importance of limiting the height of the window opening to 4 inches to prevent falls. Printed materials discuss the use of sash stops to limit the height of an open window, and operable window guards to prevent falls from open windows. These materials also inform families how these products can be obtained.

As most falls occur in multi-unit properties, it is important that the prevention message also be targeted to building owners, managers, and their tenants with young children. In Chicago, property owners must inform prospective tenants about the potential of lead exposure at the time the rental lease is signed. A similar strategy to inform tenants about window fall risks at the time of property rental might also be successful in reaching a group at risk for window falls. Educational materials could also be distributed at all single 


\section{Key points}

- In Chicago, most falls were from modest heights (2nd/ 3rd floor windows) in buildings of four or fewer storeys.

- Males aged 5 years old or younger accounted for the majority of those injured in window falls.

- Although most children in Chicago fall from lower floors, our data show a significant degree of morbidity and mortality from these falls. Head trauma was the most common injury (48\%) followed by skeletal trauma (23\%).

- In Chicago, the reported floor of a fall is a poor indicator of the height of the fall.

- Window falls prevention programmes, which include broad based public education, can be used to decrease the incidence of pediatric window falls in urban centers.

family unit property transfers. This study demonstrates morbidity from window falls among preschool children in Chicago-ongoing efforts are needed to assess the effectiveness of interventions to reduce them.

\section{ACKNOWLEDGEMENTS}

We would like to acknowledge Sameer Gafoor, James P Harisiades, $\mathrm{MPH}$, and Edward Zhovtis for their help in this project.
Authors' affiliations

N L Vish, E C Powell, D Wiltsek, K M Sheehan, Division of Pediatric

Emergency Medicine, Children's Memorial Hospital, Chicago, IL, USA

\section{REFERENCES}

1 National SAFE KIDS Campaign. Fall injury fact sheet. Washington, DC: National SAFE KIDS Campaign, 2002.

2 Spiegal CN, Lindaman FC. Children Can't Fly: a program to prevent childhood morbidity and mortality from window falls. Am J Public Health 1977;67:1143-7.

3 Barlow B, Niemirska M, Gandhi RP, et al. Ten years of experience with falls from a height in Children. J Pediatr Surg 1983;18:509-11.

4 Boston Public Health Commission Childhood Injury Prevention Program. Kids Can't Fly strategy transfer guide: models that work. Bethesda, MD: Department of Health and Human Services Bureau of Primary Healthcare, 1998:9-15

5 The Mary Ann and J. Milburn Smith Child Health Research Program Children's Memorial Institute for Education and Research. Child Health Data Lab. State \& community reports on injury prevalence \& targeted solutions. Available at http://www.chdl.org (accessed 4 August 2005).

6 Benoit R, Watts DD, Dwyer K, et al. Windows 99: a source of suburban pediatric trauma. J Trauma 2000;49:477-81.

7 Istre GR, McCoy MA, Stowe M, et al. Childhood injuries due to falls from apartment balconies and windows. Inj Prev 2003;9:349-52.

8 Lehman D, Schonfeld N. Falls from heights: not just a problem in the Northeast. Pediatrics 1993;92:121-4.

9 Musemeche CA, Barthel M, Cosentineo C, et al. Pediatric falls from heights. J Trauma 1991;31:1347-9.

10 American Academy of Pediatrics. Illinois Medicaid Facts, Available at: www.aap.org/advocacy/washing/elections/mfs_il.pdf (accessed 4 August 2005)

11 Keogh S, Gray JS, Coats TJ, et al. Children falling from a height in London. Inj Prev 1996;2:188-91.

12 Committee on Injury and Poison Prevention. American Academy of Pediatrics: Falls from heights: windows, roofs and balconies. Pediatrics 2001;107:1188-91. 